odours. Of various methods employed, he has found the method of odour 'fatigue' most helpful. Prolonged exposure to one odour reduces the sensitivity of the nose to other similar odours and often leads to striking changes in the apparent odours of other substances. In cases where no change in intensity or character of odour occurs, it may be assumed that there is no primary odour in common, and the converse should also be true. By quantitative measurements of loss of sensitivity under standard conditions of fatigue, it may even be possible to effect a quantitative analysis of odour stimuli, a line which is being pursued by Dr. Cheesman.

Dr. Duncan has concentrated on the study of the qualitative changes, supported by rough estimates of sensitivity changes due to fatigue and by more accurate odour-mixing experiments. Dr. C. M. Bean has independently carried out qualitative work on odour fatigue on much the same lines. In broad terms, the results confirm that Zwaardemaker's classification has a considerable element of truth in it.

The main difficulty in such work is to make an intelligible written record of the subjective observations; but by concentrating on a small group of odours (Zwaardemaker's classes 1 and 2), it has been possible to reach some definite results. In illustration, evidence was presented which suggests that the odour of cyclohexanol differs from that of cyclohexanone in that the former contains about 1 per cent of a component not present in that of cyclohexanone but present as a major component in the odour of tertiary butyl alcohol, while the odour of cyclohexanone contains instead about 6 per cent of a component also present as the major component in the odours of acetone, methyl ethyl ketone and tetrahydrofuran. The primary stimuli common to cyclohexanol and cyclohexanone, producing an overall minty effect, include : (I) an 'aromatic' component present in the odours of menthol, camphor, eucalyptus oil, weakly in the odour of isobutyl alcohol and very weakly in those of cyclohexane and cyclohexylamine; (2) a sweet sensation (probably stronger in cyclohexanone than in cyclohexanol), present also in menthol and more powerfully in cyclohexane and many chlorinated hydrocarbons, particularly chloroform-this sensation is stated by Henning to be due to stimulation of taste buds present in the nose; (3) possibly, but very weakly in comparison with menthol, a component stimulating the temperaturesensitive nerves in the nose.

1 Linné, K. von, Amoenitates Academicoe, 3, 195 (1756).

"Zwaardemaker, H., "Die Physiologie des Geruchs" (Leipzig, 1895). ${ }^{3}$ Henning, H., "Der Geruch" (Leipzig, 1916).

' Crocker, E. C., and Henderson, L. F., Amer. Perfumer, 22, 325 (1927).

${ }^{8}$ E. and A. Bull. No. 524 from Messrs. Eimer and Amend, New York. Fair, G. M. and Wells, W. F., J. Amer. Water Work8 Assoc.,
26, 1674 (1934).

\section{STUDY OF METEOR VELOCITIES}

$\mathrm{O}$ October 26, Dr. J. G. Porter, president of the British Astronomical Association, delivered his presidential address, taking as his subject "The Study of Meteor Velocities"*. As a result of the HarvardCornell Meteor Expedition in Arizona during 1931-33, it was believed that most meteors were moving with highly hyperbolic velocities - a conclusion which Dr. Porter never accepted. He spent some years in investigating the subject with the utmost care, and showed that the methods adopted in the Harvard-

* J. Brit. Astro. Assoc., 60, 1 (1949).
Cornell Expedition were unsound, and he found no real evidence that any meteors were hyperbolic. It is significant that none of the meteors doubly photographed by members of the Expedition showed hyperbolic velocities, and it is now generally accepted that meteors are members of the solar system. Dr. Porter's analysis of about three thousand meteor observations*, from which there were sufficient doubly observed to give the real paths of 778 , showed in addition that, contrary to the opinion of a number of experienced workers in meteoric astronomy, there was no essential difference between the heights of appearance and disappearance of the shower and sporadic meteors.

Dealing with the relation between a number of well-known meteor showers and the comets usually associated with them, Dr. Porter pointed out in his address that the usually accepted view that these meteors are the debris of the comets is open to considerable doubt. In support of the contrary view, he referred to the Leonids and Perseids which have been active for a thousand years and to the Lyrids which have been active for about two thousand years, but the comets with which they are associated were not discovered until the nineteenth century. A more convincing case is found in Comet Giacobini-Zimmer ; in 1926 the meteors associated with this comet came from particles in front of it, not from the debris following behind. Dr. Porter considers it more simple to assume that this and other comets are moving along in orbits with the dust that is responsible for the meteoric showers, such dust being quite independent of the comet, though it is just possible that in the remote past both may have been derived from a common source-perhaps from a great comet which disintegrated. Further corroboration for this view is found in the work of the Computing Section of the British Astronomical Association (of which the president is director), which was carried out during the Second World War. Of all known comets, it was shown that only sixty approached the orbit of the earth within $0 \cdot 1$ astronomical unit, while thirty-five came within 0.05 unit. There did not appear to be any connexion between these (with the exception of six) and any meteor showers-a result which is very significant if meteor showers are formed from the debris of comets.

Many other points were discussed by Dr. Pcrter ; but it is impossible to deal with all of these in this article. One important development in meteoric work referred to in the address, however, may be mentioned, namely, the application of radar to determine radiants and also speeds of meteors. Very useful work has been accomplished already, and we may confidently look forward to great strides in the near future. The discovery by radar of the great daylight streams in 1946 was a now departure in meteoric astronomy, and one can scarcely predict what further important developments will take place in the next few years. It is interesting to notice that in the past very few radiants seemed to be active in September, and this has been confirmed by radar.

In the course of the address, Dr. Porter appealed for more observers of meteors and also for more computers who would use the observational results to determine real paths. He mentioned a mechanical apparatus under construction which will facilitate such computations and will, in fact, give the heights and path-lengths of meteors directly.

* The results appeared under the title, "An Analysis of British Meteor Data" (Mon. Not. Roy. Astro. Soc. 103, 3 ; 1943 , and 104 257 ; 1945 ). See also Nature, 152, 420 (1943); 155, 761 (1945). 